\title{
Resignificaciones del desarrollo, comunidad y territorio en las prácticas comunicativas que afirman una ontología relacional. Caso Ecoaldea Anthakarana
}

\author{
Development, Community and Territory Resignifications in \\ Communicative Practices that affirm a relational ontology. \\ Ecovillage Anthakarana Case
}

\section{Miguel Manchego Chávez*}

Artículo de reflexión

Fecha de recepción: 24 de mayo de 2021

Fecha de aceptación: 21 de julio de 2021

\section{Para citar este artículo:}

Manchego Chávez, M. (2021). Resignificaciones del desarrollo, comunidad y territorio en las prácticas comunicativas que afirman una ontología relacional. Caso Ecoaldea Anthakarana. Revista Análisis Jurídico-Político, 3(6), 169-204. https://doi.org/10.22490/26655489.4769

\section{Resumen}

Este texto identifica y analiza las prácticas comunicativas que se desenvuelven dentro de una ecoaldea. Tales prácticas se fundamentan en una ontología relacional que resignifica las categorías de territorio, comunidad y desarrollo de otras maneras, en oposición a lógicas de la modernidad y el capitalismo. Estas prácticas comunicativas se convierten en el principal medio para trasmitir discursos, epistemes y premisas, con los cuales los ecoaldeanos moldean su relación con la comunidad, los seres vivos, la Madre Tierra y otros seres. Mediante una triangulación de herramientas investigativas, este estudio coteja si estas prácticas comunicativas, en correspondencia, son espacios de construcción de otros significados que se plasman en la cotidianidad, ofreciendo una resignificación

* Máster en Comunicación, Desarrollo y Cambio Social. Correo electrónico: manchegomiguel@gmail.com; ORCID: https://orcid.org/0000-0003-3078-5083 


\section{ANÁLISIS

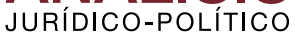

real no solo de discursos, sino de maneras de ser y hacer. El tema de investigación posibilita pensar la comunicación como el campo donde surgen transformaciones de las realidades sociales y visiones alternativas del desarrollo, desde una resistencia local frente a lo global por parte de los ecoaldeanos.

Palabras clave: ontología relacional, ecoaldea, desarrollo, comunidad, territorio.

\section{Abstract}

This paper identifies and analyzes the communicative practices that take place within an ecovillage; practices based on a relational ontology that resignify the categories of territory, community and development in other ways in opposition to the logics of modernity and capitalism. These communicative practices become the main means of transmitting discourses; epistemes and premises, with which ecovillagers shape their relationship with the community, living beings, Mother Earth and other beings. With a triangulation of investigative tools, this study compares whether, in correspondence, these communicative practices are spaces for the construction of other meanings that are reflected in everyday life, offering a real resignification not only of discourses but also of ways of being and doing. The research topic makes it possible to think of communication as the field where transformations of social realities and alternative visions to development arise, from a local resistance to the global on the part of the ecovillagers.

Keywords: relational ontology, ecovillage, development, community, territory.

\section{INTRODUCCIÓN}

Este texto expone los principales resultados obtenidos en el marco de la investigación participativa: "Resignificaciones en torno al desarrollo, comunidad y territorio fundamentadas en prácticas comunicativas que afirman una ontología relacional. Caso Ecoaldea 
Anthakarana"1 (Manchego Chávez, 2020). El objetivo general fue: analizar cómo las prácticas comunicativas de los miembros de la ecoaldea afirman una ontología relacional que resignifica su comprensión del desarrollo, el territorio y la comunidad, como opuestos a las lógicas de la modernidad y el capitalismo.

En la actualidad han emergido miradas alternativas que no están de acuerdo con las posturas oficialistas y discursos desarrollistas. Estas, se enmarcan en lo que se denomina "posdesarrollo", donde se encuentran planteamientos ecosocialistas, del buen vivir/vivir bien, etnodesarrollo, ecofeminismo, desarrollo propio, transdesarrollo, entre otros. Estas posturas tienen como semejanza hallar otras dinámicas acerca de lo que se ha entendido por desarrollo.

Desde los años 90 movimientos alternativos plantean cuestionamientos de fondo a esa categoría y sus diversas manifestaciones. Entre estas críticas, Gudynas (2017) diferencia cuatro vertientes analíticas. La primera, denuncia el fracaso generalizado del desarrollo y postula la necesidad de abandonarlo como discurso y política. La segunda, afirma que representa una creencia, mito o religión occidental que se impone a otras culturas. La tercera, lo cuestiona: toma como problema central el papel del crecimiento económico y demanda, en contraste, el decrecimiento. La cuarta, lo valora como un discurso que expresa premisas como la modernización o la apropiación de la naturaleza desde una pretensión de verdad universal, por lo que se subordinan otras culturas (Gudynas, 2017). Por ello estas corrientes del posdesarrollo apuestan por cuestionar el desarrollo oficial y terminar su hegemonía.

Fruto de las críticas al desarrollo y la visibilización de sus consecuencias negativas, se consolida el movimiento de ecoaldeas a nivel global $^{2}$ el movimiento de las Ecoaldeas; comunidades intencionadas que experimentan un estilo de vida ecológico, comunitario y antihegemónico. Las cuales funcionan bajo lógicas de propiedad, producción y cotidianidad que se establecen como alternativas

1 Trabajo de grado para concluir el máster en Comunicación, Desarrollo y Cambio Social de la universidad Santo Tomas. Colombia.

2 La Red Global de Ecoaldeas (GEN, por sus siglas en inglés) se funda oficialmente en 1995 como respuesta directa a la Cumbre de la Tierra, organizada por la ONU en Río de Janeiro en 1992, y la declaración resultante llamada Agenda 21 (Valdes y Ricalde, 2006) 
materiales y espirituales a la vida en la ciudad y a las problemáticas de la sociedad capitalista y moderna.

Las ecoaldeas son comunidades donde las personas se asocian por voluntad propia, la mayoría están integradas por migrantes de las urbes, clase media, que buscan priorizar el bienestar de los humanos y de los ecosistemas tanto presentes como futuros. Las ecoaldeas presentan un alto nivel de participación y organización, pero sobre todo de autodeterminación, por lo que alcanzan un grado de responsabilidad y resiliencia para afrontar las crisis que se puedan generar en el proceso de convivencia o en su entorno (Muñoz Villarreal, 2017).

Las propuestas de los ecoaldeanos se desarrollan en medio de las problemáticas sistémicas. No esperan a que otros brinden soluciones —el Estado, las instituciones o las empresas-, buscan solucionarlas colectivamente. Construyen comunidad a pesar del individualismo y otros valores modernos. Fortalecen los tejidos sociales y la identidad dentro de sus territorios sustentables, armoniosos con la Madre Tierra, espacios de paz y desarrollo biocéntrico. Estudiar estas experiencias, que no están visibilizadas en la esfera pública, citadinas y mediáticas, constituye un insumo relevante para replantear conceptos y alternativas al desarrollo, que son urgentes para superar la crisis civilizatoria y ambiental en la que estamos inmersos.

\section{Antecedentes}

El antecedente occidental más influyente para el retorno de la población citadina al campo está en los inicios del movimiento hippie, década del 60 en los Estados Unidos, y la revolución de mayo de 1968 en Francia. Estos fenómenos comparten ideas sobre la oposición al capitalismo, el retorno a la naturaleza y el rechazo al estilo de vida de las ciudades y los valores burgueses (Pinzón, 2014). Otras posibles influencias más antiguas pueden ser experiencias como las comunidades Ashrams en la India, los Lamas en el Tíbet, los Amishes en Estados Unidos y los Ayllus de los Andes (Ruz Buenfil, 2006). 
En la actualidad, las ecoaldeas impulsan modos de vida alternativos acompañados por una resignificación de los modos de vida rural, campesina, indígena y ancestral. Reconocen la necesidad de reconectarse con la naturaleza; priorizar la producción y consumo local; la autosuficiencia económica y alimentaria, la obtención y generación de recursos mediante procesos sostenibles y ecológicos; abandonar la dependencia de energías fósiles; reducir el consumismo, la explotación laboral y la lógica de mercado; consolidar propiedades comunales; y sostener trabajos e ingresos comunitarios como agricultura, artesanías, ecoturismo, medicinas alternativas, educación y otros. De esa manera, adoptan comportamientos individuales y sociales relacionando valores, estilos de vida, formas de producción, tecnologías, políticas y estructuras sociales (Buil, 2007).

En Colombia, el movimiento de ecoaldeas surge a comienzos de los años 70 con el proyecto Las Gaviotas en el Guaviare. Más adelante, se crean otras como la Ecoaldea Sasardí, Aldeafeliz (Muñoz Villarreal, 2017) y muchas otras nuevas. Esto ha articulado y fortalecido un movimiento que responde a las problemáticas del modelo neoliberal en el territorio colombiano, poniendo a disposición modelos alternativos y sostenibles (Solórzano Duran, 2017). El fenómeno se intensificó a partir de los años 90 y en los 2000 se establecen redes nacionales de ecoaldeas (Renace, Casa Colombia). En la actualidad, se consolidan eventos anuales que permiten la articulación de sus integrantes (Llamado de la Montaña, Espejo, Bioconstruyendo, entre otros). A pesar de las diversas experiencias en el país y su antigüedad hay escasas investigaciones sobre el tema y ninguna profundiza sobre la comunicación inserta en las lógicas alternativas planteadas desde las ecoaldeas.

Las investigaciones colombianas consultadas (Pinzón 2014; Guevara 2014; Aleman 2017; Duran 2017; De la Morena 2017; Muñoz Villarreal 2017) exhiben desde distintas miradas las causas por las cuales los individuos asumen el reto de conformar ecoaldeas. En ellas se observa dos motivos constantes: el primero, resistencia al capitalismo y la 
modernidad ${ }^{3}$, como causantes de las principales problemáticas sociales y ambientales; el segundo, corresponde a la búsqueda espiritual para el crecimiento personal y estilos de vida que armonicen con la naturaleza y todos los seres. Las investigaciones también presentan duras críticas y dudas sobre el objetivo y resultado de conformar ecoaldeas; objetivos y resultados que aún no cambian a fondo las estructuras y lógicas dominantes, aunque en el discurso se pretenda hacerlo.

No obstante, según estos autores, existen resultados concretos en las ecoaldeas, como el cambio de la relación humanidad-naturaleza, una reconfiguración de la naturaleza y una reconexión con ella, pues se establece una relación profunda y sagrada en tanto que la tierra provee un soporte espiritual, emocional y material. Así, se puede evidenciar la construcción de otros sentidos que se hacen en torno al territorio y el desarrollo.

\section{Metodología}

La investigación tuvo un enfoque cualitativo, basado en el método del estudio de caso de tipo descriptivo, ya que fue dirigido a

3 Escobar (2005) caracteriza la modernidad de la siguiente manera: 1) históricamente la modernidad tiene orígenes temporales y espaciales identificados en el siglo XVII de la Europa del norte (especialmente Francia, Alemania e Inglaterra), alrededor de los procesos de la Reforma, la llustración y la Revolución Francesa; 2) sociológicamente la modernidad es caracterizada por ciertas instituciones, particularmente el Estado-nación, y por algunos rasgos básicos: como la retroalimentación entre el conocimiento experto y la sociedad, la descontextualización de la vida social del contexto local y el distanciamiento espacio/tiempo; 3) culturalmente la modernidad está caracterizada por la apropiación de las competencias culturales por las formas de conocimiento experto asociadas al capital y a los aparatos administrativos del Estado, es decir, la modernidad introduce un orden basado en los constructos de la razón, el individuo, el conocimiento experto y los mecanismos administrativos ligados al Estado; 4) filosóficamente la modernidad implica el surgimiento de la noción de "hombre", separado de lo natural y lo divino, como el fundamento de todo conocimiento y orden en el mundo (antropocentrismo). Además, se desarrolla la teoría de que el mundo está compuesto por cosas y seres cognoscibles, por lo tanto, controlables. Al mismo tiempo, Escobar (2005), desde una perspectiva decolonial, expone las distinciones que la conceptualización modernidad/colonialidad hace de la anterior caracterización, ya que la perspectiva decolonial toma en cuenta: 1) el surgimiento de los orígenes de la modernidad en la conquista de América y el control del Atlántico a partir de 1492 (mucho antes de la ilustración); 2) presta atención al colonialismo, poscolonialismo e imperialismo como constitutivos de la modernidad; incluyendo la economía y sus formas de explotación; 3) adopta una perspectiva global en la explicación de la modernidad, en lugar de una visión de la modernidad como un fenómeno intraeuropeo; 4) identifica la dominación de otros afuera del centro europeo como una necesaria dimensión de la modernidad; 5) identifica el eurocentrismo como una representación hegemónica y modo de conocimiento que arguye su propia universalidad, en cuyo centro reside la negación de la alteridad. 
comprender las dinámicas presentes en un contexto singular. En ese sentido, Martínez Carazo (2006) señala que la mayor fortaleza del estudio de caso radica en que este mide y registra la conducta de las personas involucradas en el fenómeno estudiado. Al mismo tiempo, los datos pueden ser obtenidos desde una variedad de fuentes, tanto cualitativas como cuantitativas. Para cumplir el método, la investigación realizó las etapas del análisis inductivo de información cualitativa:

1. Recolección de la información (trabajo de campo)

2. Estructuración y organización de los datos

3. Codificación de los datos (comparación de los datos con la literatura)

4. Conceptualización y explicación del problema

5. Socialización y ajuste de los resultados (feedback)

6. Elaboración de la tesis.

El principio de triangulación, para garantizar la validez interna de la investigación, permitió verificar si los datos obtenidos a través de las diferentes fuentes de información guardan relación entre sí. Es decir, si desde diferentes perspectivas convergen los efectos explorados en el fenómeno objeto de estudio (Martínez Carazo, 2006). En consecuencia, para esta investigación se utilizaron las siguientes fuentes de información: observación participante, diario de campo, entrevistas semiestructuradas, grupo focal y un análisis del discurso. En este último se analizaron las letras de 17 canciones representativas, interpretadas por los ecoaldeanos dentro de la ecoaldea y sus eventos.

La observación participante se realizó en cuatro momentos. La primera etapa, a manera de acercamiento, consistió en participar en uno de sus eventos públicos: un temazcal ${ }^{4}$ realizado en septiembre de 2018. El segundo momento fue para consolidar mi relación con los eco aldeanos, conocer más de cerca sus actividades y confirmar su participación en la investigación; para ello alargué a una semana

4 La ceremonia de temazcal consiste en un baño de vapor que se traduce en un proceso de purificación físico a través de la sudoración y un proceso de reconexión con el Gran Espíritu, la Madre Tierra y los cuatro Elementos a través de los desarrollos piscoemotivos que surgen en su interior. 
mi estadía en noviembre de 2018. En agosto del 2019 inicié el trabajo de campo: observación participante y diario de campo. Por tal motivo me mudé a la ecoaldea y residí allí de agosto hasta octubre de ese año. En enero del 2020 continué otro periodo de residencia, desde enero hasta abril, y con ello prosiguió el trabajo de investigación; se concluyeron las herramientas iniciadas y se aplicaron las entrevistas semiestructuradas, el grupo focal y la triangulación. Además, en ese tiempo participé en un evento ecoaldeano realizado a nivel nacional, el Llamado de la Montaña 2020 con el cual sumé aportes y diversifiqué los insumos para esta investigación. Paralelamente a las dos residencias y al evento realicé el análisis del discurso.

\section{Descripción de la Ecoaldea Anthakarana}

La Ecoaldea Anthakarana está ubicada en Salento, Quindío, Colombia. La idea de conformar esta ecoaldea nació en el 2008, pero fue constituida en el 2012. Actualmente viven dentro de ella una pareja de adultos mayores, hombre y mujer, los fundadores de la aldea. En otra casa vive la hija de ellos junto a su compañero, quienes tienen dos hijas, de 6 y 9 años respectivamente. En otra cabaña vivía una residente sola. El hijo de los fundadores tiene estrecha relación con su ecoaldea y la visita asiduamente, aunque regularme vive en Armenia, Quindío, junto a su hija de 4 años. Además, el proyecto de Anthakarana se expande junto a vecinos del territorio: una familia compuesta de una colombiana y un francés con su hijo de 10 años y su hija de 6 años; una mujer de Bogotá y una mujer de Argentina. A la comunidad los une el llamado de la Madre Tierra y cierto rechazo u oposición al sistema hegemónico.

Por otra parte, la ecoaldea acepta voluntarios que quieran trabajar en el territorio y compartir experiencias. En el transcurso de mi estadía han visitado la ecoaldea más de 15 personas como voluntarios momentáneos.

El terreno tiene aproximadamente cinco hectáreas, un nacimiento de agua, una quebrada, bosque nativo y reforestado, y huertas en forma de terrazas. En ellas se siembra, aunque en poca cantidad, mucha diversidad: maíz, quinua, amaranto, habas, frijoles, yuca, plátanos, tomates, cebollas, papas, piña, arvejas, bore, arracacha, rábanos, especies, aromáticas y plantas medicinales, entre otras. 
Miguel Manchego Chávez - Resignificaciones del desarrollo, comunidad y territorio en las prácticas comunicativas que afirman una ontología relacional. Caso Ecoaldea Anthakarana

En cuanto animales, se crían gallinas para obtener huevos y cabras para obtener compost.

\section{Resultados}

\subsection{Prácticas comunicativas ${ }^{5}$ Que afirman una ontología relacional ${ }^{6}$}

La importancia de analizar su ontología es que a partir de ella se determina qué es lo existente, lo legítimo y lo verdadero en el mundo. Esto, claramente guía las maneras de entender las categorías que correspondan a estas determinaciones. En el caso de la ecoaldea, se señala que la presencia de una ontología relacional — distinta a la moderna-genera otras maneras de entender el territorio, la comunidad y el desarrollo.

Para identificar la ontología presente en la ecoaldea, se estudiaron las prácticas comunicativas y los eventos en las que se participó. Las prácticas comunicativas se caracterizaron por ser dependientes de matrices culturales consolidadas en el proceso de reconocimiento y validación de la diferencia. El campo cultural-comunicativo que generan las prácticas alternativas es un campo de luchas por la representación como sistemas de sentido, que buscan ser disruptivo al discurso dominante.

5 Las prácticas comunicativas son aquellas que posibilitan acciones y dinámicas alrededor de los medios y sus mediaciones, sin embargo, van más allá, incluyendo acciones y expresiones cotidianas de sentidos complejos, expresiones artísticas, formas de organización, rituales y otras acciones. Estas prácticas comunicativas manifiestan y profundizan esfuerzos de creación, transformación, recuperación y conservación de sentidos, redes y lazos, que pueden conllevar cambios profundos y la construcción de alternativas a un orden social imperante (Valencia y Magallanes, 2015).

6 El concepto de ontología que usamos alude a la categoría trabajada por Arturo Escobar (2012) en conjunto con Blaser y De la Cadena (2009), la cual no asume una realidad única y trata de visibilizar la noción de mundos diversos sin negar lo real. Estos autores plantean cambiar el término de cultura por el de ontología al momento de analizar los movimientos sociales, ya que el concepto de cultura implica la existencia de una única realidad y múltiples versiones de ella, mientras que el de ontología supone la existencia de múltiples realidades posibles. Para Escobar hay muchas formas de expresar la relacionalidad; un principio clave es que la realidad está formada de entidades que no preexisten a las relaciones que las constituyen; otra forma de explicar las ontologías relacionales es que son aquellas en las cuales los mundos biofísicos, humanos y supernaturales no se consideran como entidades separadas, sino que se establecen vínculos de continuidad entre ellos; una forma más de referirse a lo relacional es no existe la división entre naturaleza y cultura como la conocemos, mucho menos entre individuo y comunidad (Escobar, 2014). 
A continuación, se describen las prácticas más relevantes y se señala cómo sustentan una ontología relacional:

\subsubsection{La terapia Homa}

Es una ceremonia para la purificación del territorio que se realiza casi diariamente al atardecer. Esta práctica consiste en colocar agradecimientos, rezos e intenciones sobre un pequeño fuego encendido en un brasero. Primero se enciende el fuego con unas tablas de excremento seco de vaca (compradas o realizadas en la ecoaldea), para ayudar a su combustión se le agrega ghee (mantequilla clarificada). Los participantes se sientan en el piso formando un círculo alrededor del fuego. Mientras arde, se cantan versos en sánscrito, que pueden estar acompañados de percusión. Luego, se verbalizan las intenciones de la ceremonia colocando algunos granos de arroz dentro del fuego. Al concluir, se da un momento para que los participantes entreguen sus rezos o intenciones, ya sea en voz alta o mentalmente.

Esta práctica comunicativa afirma una ontología relacional al reconocer el territorio como un ser con el cual relacionarse con agradecimiento y del cual depende la propia existencia humana. Al ser el humano quien hace un rito en pro de la salud de su territorio, refleja la estrecha relación que se tiene con él. De igual modo, mediante la petición de favores al territorio, se le reconoce como un componente esencial para el desarrollo de la vida humana. Estos aspectos concuerdan con la relacionalidad, que puede referirse a la inexistencia de una división entre naturaleza y cultura (Escobar, 2012). Por otro lado, los discursos que se desenvuelven durante sus cantos, en su mayoría hacen referencia a una ontología relacional.

\subsubsection{Círculo de PALABRA}

Es una práctica realizada en una casa de pensamiento, en la que participan los miembros de la ecoaldea sentados en círculo alrededor de un pequeño altar de piedras instalado en el centro de la estructura. La facultad de hablar - la palabra - se la usa por turno, lo que permite que todos puedan hablar en su momento. Esto, incurre en la obligación de escuchar a los otros y esperar sin interrumpir hasta que el círculo de persona se haya expresado y le corresponda 
el turno. Por lo general, se usa para tratar temas importantes o decisiones dentro de la ecoaldea. Esta práctica no tiene una duración definida, puede ser tan larga como requiera el asunto a tratar.

Otra modalidad de círculo de palabra es cuando su propósito es "tejer la palabra". En ese caso, la convocatoria para la reunión no tiene un objetivo final que alcanzar; se trata de un ejercicio grupal para expresarse, dejando que la inteligencia colectiva sea la que vaya guiando los temas de conversación. Justamente por eso se le llama "tejer la palabra". Cada quien deja salir su "palabra"(lo que quiera expresar), que vendría a ser una "hebra" que se entrelaza con las otras, formando así el "tejido" (la suma de las conversaciones).

Esta práctica comunicativa afirma una ontología relacional al reconocer que en la comunidad no existe un individuo que sea el centro o esté por delante o encima de los otros, sino que todos están en el mismo nivel. Esta práctica denota que son interdependientes y que las relaciones con otros son necesarias para constituir la comunidad. Lo anterior concuerda con la relacionalidad que puede referirse a la inexistencia de una división entre individuo y comunidad (Escobar, 2012).

\subsubsection{Temazcal}

Es un baño de vapor realizado dentro de un inipi, una estructura convexa cubierta por pesadas telas que representan el vientre de la Tierra. El propósito de las telas es tapar toda la luz y retener el vapor que se genera al rociar piedras calientes con agua. Los participantes se sientan sobre el piso formando un círculo alrededor de las piedras. La ceremonia se realiza en total oscuridad o levemente iluminada por las rocas. Los guías empiezan a cantar acompañados por instrumentos de percusión como el tambor lakota y sonajas; el canto es seguido por los participantes. Además del canto, hay momentos de reflexión, enmarcados en caminos espirituales o filosóficos, en problemáticas ambiental, relaciones intrapersonales, interpersonales, entre otros temas. Así mismo se abren espacios para que cualquier participante inicie un canto o exprese un rezo personal. El temazcal predispone a los participantes a estar en un estado de concentración a partir de poner su cuerpo y su mente en un estado de atención. Con ello se logra la intervención de seres elementales o espirituales. La ceremonia del temazcal instaura un proceso de sanación físico, 
mental y espiritual, comprendiéndolo como un solo estado de salud interrelacionado. La ceremonia dura aproximadamente dos horas.

Esta práctica comunicativa afirma una ontología relacional, primero, al reconocer que los mundos biofísico, humano y sobrenatural o espiritual no se consideran como entidades separadas, sino que se establecen vínculos de continuidad entre ellos. Esto principalmente se comprende mediante los cantos, que enuncian estas premisas, y los discursos o rezos que viabilizan una trasmisión de estos principios ontológicos. Segundo, el temazcal rompe con el dualismo de lo humano/no humano (elementos, elementales, energías) y su posible relación dialógica que se logra al participar de esta ceremonia. Tercero, con la disposición en círculo de los participantes existe una ruptura de la dualidad individuo/comunidad, pero esta ruptura también se expresa con la comprensión de que existe una familia consanguínea, una familia extendida —otras personas, la misma comunidad - y una familia formada por todas las relaciones - relaciones con seres no humanos, el territorio, el mundo biofísico, el mundo espiritual, entre otros-.

\subsubsection{El Llamado de la Montaña}

Es un encuentro ecoaldeano masivo con 14 años de trayectoria. El Llamado de la Montaña del año 2020 consistió en un evento de siete días, donde se reencontraron y reconocieron los miembros de las ecoaldeas colombianas, además de otras personas, familias y proyectos relacionados con estilos de vida alternativos y prácticas sustentables. Dentro de sus actividades tuvieron un mapeo de actores; talleres teóricos y prácticos sobre diferentes temas relacionados con la sustentabilidad y la comunidad; foros sobre el buen vivir, derechos de la Madre Tierra y cambio climático; espacios para trueques de productos artesanales; círculos de palabras y mambeaderos; olimpiadas ecoaldeanas; eventos culturales y festivales musicales. Además, en sí mismo, el evento es un ejercicio de vida en comunidad y sustentabilidad. De comunidad por que durante los siete días conviven 180 personas, entre familias, parejas, grupos de amigos y personas solitarias de distintas edades, lenguas y culturas, las cuales logran llevarse amenamente a pesar de las diferencias. Estas personas tienen que asentarse en espacios comunales para acampar, compartir los mismos recursos y generar dinámicas para la cotidianidad 
como: horarios de baño, labores diarias, cocina, almuerzos, esparcimiento, participación, integración, horarios de sueño, etc. También es un ejercicio de sustentabilidad porque se aprende sobre el uso y mantenimiento de baños secos, ahorro de agua en el aseo personal y lavado de vajilla, compostaje de residuos orgánicos, entre otros. Conjuntamente desarrollan talleres específicos para profundizar otras dinámicas ecosostenibles.

El Llamado de la Montaña afirma una ontología relacional mediante discursos y prácticas formales en sus foros, talleres y actividades programadas. Entre los más relevantes están los foros sobre los paradigmas del buen vivir y la ley de origen, que manifiestan la interrelacionalidad, interdependencia y complementariedad de todos los seres y la Madre Tierra. También se confirma con las iniciativas en pro de los derechos de la Madre Tierra, ya que la reconocen como un sujeto de derecho y no como un objeto de dominación. Por otra parte, los talleres de permacultura y bioconstrucción inician una ruptura en la ontología dual moderna - humano/naturalezaal afirmar desde prácticas ecológicas comprensiones similares a los paradigmas anteriores. Los talleres de sociocracia ${ }^{7}$ que se implementan inician también una ruptura con la concepción dualista individuo/comunidad.

Las ceremonias, prácticas espirituales o de crecimiento personal que se realizan en el marco del evento también afirman una ontología relacional al comprender que los seres no preexisten a las relaciones que los constituyen y, en ese sentido, tampoco a la realidad.

\subsubsection{LAS MEDICINAS}

Es el denominativo que abarca el mambe, ambil, rapé, tabaco, coca, poporo y otras sustancias, así como a sus procesos de consumo.

Considero las medicinas como prácticas comunicativas, apoyado en los planteamientos de Valencia y Magallanes (2015), para quienes las prácticas comunicativas van más allá de acciones o dinámicas

\footnotetext{
7 La sociocracia refiere a un modo de toma de decisiones y de gobierno, que le permite a una organización comportarse como un organismo vivo, es decir autoorganizarse y autocorregirse. Su fundamento moderno se basa en las teorías sistémicas. El objetivo más importante es el de desarrollar la coparticipación y corresponsabilidad de los actores, otorgando poder a la inteligencia colectiva al servicio del éxito de la organización (Red Casa Latina, 2019).
} 
alrededor de los medios y sus mediaciones; incluyen acciones, expresiones y rituales que intercambien sentidos. Es así como la manera de hacer, dar y tomar medicina -el ritual implícito en esas acciones - tiene un componente comunicativo dialógico. Por otra parte, Herrera y Vega (2014) señalan que en cada escenario en donde se lleva a cabo una experiencia comunicativa, los actores de la experiencia desarrollan un conjunto de acciones prácticas. Estas son producto de una lógica de acción que hace parte de un conglomerado de disposiciones del sistema en el cual se desenvuelve. Es decir, las prácticas legitiman la posición que asumen los actores al interior del escenario. En la práctica misma se reproducen significaciones y, desde allí, se abordan las prácticas culturales como prácticas comunicativas. Por lo tanto, la propia acción práctica de hacer/dar/recibir medicina reproduce significaciones que se comparten o intercambian entre los participantes, lo cual afirma también el componente comunicativo de los rituales de medicina.

Las medicinas afirman una ontología relacional al crear una ruptura de la división humano/naturaleza. Las plantas, comprendidas como medicina, tienen una mayor interrelación con los individuos y generan mayores vínculos relacionales. La naturaleza y la vida se comprenden como sujetos de comunicación, que pueden manifestarse al estar el humano dispuesto a percibir los mensajes inmanentes presentes a su alrededor, o presentes al tomar la medicina que ellas mismas ofrecen. Así mismo, por ser las medicinas formas de relacionarse con otros, no separa lo racional de lo sentimental, ya que el proceso comunicativo puede ser mental, psicológico, emotivo, físico, sensorial, energético y espiritual, y complementarse entre ellos.

Herrera y Vega (2014) señalan que las prácticas comunicativas se caracterizan por ser dependientes de matrices culturales. En el caso de la Ecoaldea Anthakarana, se observa que la matriz cultural es una hibridación de varias otras que, aunque provenientes de distintos puntos geográficos, confluyen en la ontología que guardan. Entre sus referentes tienen las culturas indígenas andinas, amazónicas, del centro y norte del Abya Yala. En menor medida también toman elementos de culturas asiáticas e indias. 
Las prácticas halladas en la ecoaldea, caracterizadas desde las perspectivas que plantean Herrera y Vega (2014), son dos: las primeras corresponden a las prácticas comunicativas de resistencia - presentes en la terapia Homa, el Temazcal, los círculos de palabra y los cantos - resisten primero al olvido y al descarte, y segundo a la hegemonía de los medios masivos, con todo lo que ello conlleva: hegemonía cultural, representativa, estética, etc. Estas prácticas de resistencia funcionan como medios alternativos - con componentes ancestrales - para construir y compartir discursos que intentan hacer rupturas frente a los discursos dominantes, entre ellos el papel de la Tierra, la dominación de la naturaleza, la racionalidad instrumental y la dualidad racional. Las segundas las constituyen las prácticas comunicativas proyecto - como el Llamado de la Montaña-, que conectan la comunicación con los procesos o movimientos sociales (ecoaldeas, pueblos en transición, derechos de la madre tierra). De esta manera se plantean los escenarios comunicativos como plataformas de construcción de sentidos y acciones alternativas.

Entre ellas, considero el "Llamado de la montaña" como la principal práctica pública y masiva, que busca acceder a un espacio de poder, entendiendo el "poder" como la capacidad de transformar la mentalidad de las personas y desarrollar procesos con lógicas y referentes distintos. Es decir, se constituye como una práctica que incide con discursos y acciones concretas, superando la simple crítica académica.

Por otra parte, en las prácticas comunicativas de la Ecoaldea Anthakarana se encuentran elementos que instauran o refuerzan una ontología relacional, siendo esta una característica unificadora. La mayoría de las prácticas comunicativas presentes en la ecoaldea manifiestan que entidades como la Madre Tierra, el Gran Espíritu, los ancestros, los espíritus, los elementos, las energías, los animales, las piedras, las plantas y la humanidad, estamos interrelacionados e interdependemos unos de otros. Esto reconoce formas de conceptualización de la naturaleza diferentes al naturalismo moderno. Además, estas prácticas comunicativas instauran acciones de complementariedad entre diversos elementos y la reciprocidad de funciones y responsabilidades, con la correspondencia de estas. Esto transforma la 


\section{ANÁLISIS

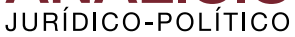

concepción de la dualidad hacia la paridad ${ }^{8}$, coincidiendo con el giro ontológico en su interés por plantear alternativas al dualismo entre naturaleza y cultura, lo que estructuró el naturalismo moderno (Ruiz y Del Cairo, 2016).

\subsection{Análisis de la ontología relacional pResente en la ecoaldea}

El análisis del discurso permite señalar que la ontología ecoaldeana comprende una relación estrecha con la Tierra al reconocer la propia humanidad como una más de sus hijas, es decir la tierra o naturaleza como un gran ser vivo que crea y sostiene a la vida. De esta manera se reconoce a la Tierra como sujeto y ser vivo. Asimismo, es una ontología que comprende la relación con los elementos - tierra, agua, aire y fuego- como los fundamentos que compartimos con todos, y las manifestaciones de estos elementos como los sostenedores de la vida. Por lo tanto, estos comprenden una relación familiar, afectiva, con todo lo que nos rodea. Además, esta ontología valora el ser en plural, es decir la existencia en colectividad, en comunidad, en interrelación.

En los discursos analizados, los ecoaldeanos señalan el deber de cambiar de paradigma y volver a las compresiones que ayuden o generen una relación de armonía con la Tierra y la vida. Por otro lado, no reconocen dualidades opuestas, sino paridades complementarias. Al negar la división humanidad/naturaleza y reconocer la interrelación e interdependencia con la Tierra, la naturaleza y todos los seres vivos son asimilados como miembros de una gran familia, quienes cumplen una función dentro de ella, al igual que el humano.

Por otra parte, se comprende una relación dialógica con la Tierra; es decir que ella se comunica con la humanidad y la humanidad con ella. Con esta conexión dialógica se reconocen las influencias de la Tierra y la naturaleza sobre la humanidad. Esta comprensión ontológica también está basada en el reconocimiento y agradecimiento a la vida, sin distinciones respecto a lo que suceda en ella.

8 Elementos pares, considerados contrarios, pero no excluyentes, sino complementarios, equilibradores, cocreadores; necesarios ambos. Una referencia directa podría ser el ying y el yang; y el chacha warmi. 
En los cantos se destacan los cuatro elementos como fundamento de todo lo que existe en el universo; por lo tanto, la relación entre el ser humano y todo lo que lo rodea o existe se vuelve más cercana. A su vez, plantean que el todo estaría en las partes, así como las partes conformarían el todo. Por lo cual, como individuos poseemos las mismas cualidades y capacidades de esa totalidad. Se reconoce así la validez de ser distinto, pero consciente del nexo guardado en nuestra esencia.

Los ecoaldeanos también afirman una ontología donde la emoción y la razón, el espíritu y la materia no están separados. Reconocen una relación estrecha entre los procesos psicológicos, emotivos y espirituales, y la realidad que se forma a través de ellos. En ese sentido, el individuo es el producto, pero también el productor de la realidad en la que se encuentra.

Su ontología es integradora al permitir ser, al mismo tiempo, objeto y sujeto. Estos conceptos no son opuestos separados, sino paridades que se constituyen mutuamente. A su vez, la ontología planteada es cíclica; el tiempo y el espacio no se desplazarían progresivamente, ni linealmente hacia un fin, sino que se repetirían en ciclos. La propia vida sería un proceso circular, el cual se genera y se extingue para volver a generarse. Por ello se deben adoptar modos de vida que armonicen con los ciclos naturales, donde lo fundamental sería dejar fluir ese devenir de la existencia.

Para complementar, en las entrevistas, los ecoaldeanos expresaron rasgos puntuales de su ontología relacional. Ellos entienden a la Tierra como un ser vivo, sujeto de derecho, sintiente. Por ello adoptan el "biocentrismo" como postura en la que el ser humano no es el centro de la vida; la Tierra y la vida son el centro de todo. En ese sentido, especifican que el humano depende de cada una de sus relaciones para mantener el equilibrio de su existencia. Por lo tanto, esas relaciones deben ser responsables, respetuosas y de gratitud. Los ecoaldeanos se relacionan con la Tierra, la vida y otros seres con el propósito de estar en equilibrio. Si ellos están en equilibrio, también el humano lo estará de manera interna y externa. Algunas de sus formas para lograrlo son: hacer ofrendas al agua, a la Tierra, al fuego y al aire; realizar pagamentos y rezos; y consumir mambe y ambil.

Desde algunas observaciones a partir del diario de campo, se evidenció, en primer lugar, que el propio nombre de la ecoaldea implica 
una ontología relacional. Anthakarana significa "unir lo visible con lo invisible, el cielo con la Tierra, la materia con el espíritu". Asimismo, los ecoaldeanos tienen una fuerte identificación con pensamientos neoindígenas disimiles a la ontología moderna: el camino rojo ${ }^{9}$ proveniente de los indígenas de norteamérica, el buen vivir ${ }^{10}$ proveniente de los indígenas andinos, la ley de origen ${ }^{11}$ proveniente de los indígenas de Colombia (muiscas y quimabayas), entre otros. Los ecoaldeanos expresan que la misión del mestizo es ser el nexo entre el pasado y el devenir, entre el indígena y el occidental, con lo cual logran una conciliación entre sus orígenes étnicos, su procedencia citadina, sus nuevas filiaciones culturales y su permanencia rural. La hibridación entre diferencias culturales —ontológicas - constituye la comprensión de que todas, de algún modo u otro, llevan al mismo punto. En ese sentido especifican que prefieren el "camino del medio", lo cual implica no aferrarse a ningún extremo, sino poder transitar todos en su justo medio. Así mismo, en su diario vivir reconcilian saberes científicos y ancestrales, teniendo ambos el mismo nivel de validez en su aplicación, principalmente en lo concerniente a la agricultura. También se observa que los ecoaldeanos se guían, de manera efectiva, por la intuición, revalorizando esta clase de inteligencia al nivel de la racional.

Por otra parte, existe una conciencia de que una relación afectiva con el territorio y las plantas hacen que estas crezcan saludables. Los ecoaldeanos conversan con las semillas, las plantas y los animales que cuidan, logrando generar empatía con ellos y una ética del cuidado mayor. También los ecoaldeanos se relacionan con los

9 The Red Road is a path, away. It's full meaning is the way one acts, the methods one uses, and what directs one's doing. There is more to the Red Road then spoken word or written words on paper. It is behavior, attitude, a way of living, a way of "doing" with reverence of walking strong yet softly, so as not to harm or disturb other life. (Redtail Freesoul, 1986).

10 Buen vivir es el eje filosófico del pensamiento y actuación individual y colectiva de los pueblos indígenas. Implica una relación indisoluble e interdependiente entre el universo, la naturaleza y la humanidad, donde se configura una base ética y moral favorable al medio ambiente, el desarrollo y de la sociedad, en la que se manifiestan y se hacen necesarios la armonía, el respeto y el equilibrio (Rodríguez, s. f.).

11 La ley de origen es la ciencia tradicional de la sabiduría y del conocimiento ancestral indígena para el manejo de todo lo material y lo espiritual. Su cumplimiento garantiza el equilibrio y la armonía de la naturaleza, el orden y la permanencia de la vida, del universo y de los mismos pueblos indígenas guardianes de la naturaleza. Asimismo, regula las relaciones entre los seres vivientes, en la perspectiva de la unidad y la convivencia en el territorio ancestral legado desde la materialización del mundo (Consejo regional indígena del Huila [CRIHU], 2013). 
seres invisibles a través de sus ceremonias, ofrendas, cantos, terapias, medicinas, meditaciones, altares y prácticas (poporo, mambe, ambil, chicha dulce, pagamentos, rezos, toques de tambor, temazcales, sahumerios, entre otros). Con ello existe una conciencia de una intervención en la realidad material al relacionarse con los elementales y espíritus. Al mismo tiempo, en sus ceremonias y prácticas se reza por la familia consanguínea (núcleo familiar), la familia extendida (comunidad) y por todas las relaciones (humanas, animales, vegetales, espirituales). En ese sentido todo es familia. "Todo es mi familia, familia. Todo es sagrado; plantas y animales, todo es sagrado; Tierra, cielo y mar. Todo es mi familia, familia" (canto grupal Toque de tambor, marzo 2020).

Otro punto en el que se manifiesta la relacionalidad es que no creen que existan las casualidades, existen las causalidades, es decir una causa y un efecto, una acción y una reacción. A su vez, los ecoaldeanos relacionan lo positivo y negativo como paridad, en lugar de dualidades separadas. Sin dolor, esfuerzo o el mal, no se existe; estos también son necesarios, al igual que la alegría, el descanso y el bien.

A partir de esas formas de comprensión de la realidad y su manera de relacionarse con ella se evidencian guías para que los ecoaldeanos resignifiquen las categorías de territorio, comunidad y desarrollo. A continuación, se señalan dichas resignificaciones.

\subsection{Resignificaciones en RELAción CON EL TERRITORIO}

A partir del análisis de sus discursos, se aprecia cómo el territorio adopta diferentes matices para los ecoaldeanos. En primer lugar, el territorio - terrestre como tal- está asociado con otros elementos: agua, ríos, viento. En segundo lugar, se concibe una relación afectiva con este, como familia, madre, Pachamama, útero, casa, amor. De esta manera se reconoce el territorio como un ente femenino, un espacio que genera y soporta la vida; por lo tanto, es sagrado. De esta comprensión se deriva el tipo de relación estrecha que el humano debe tener con el territorio, de amor, respeto, cuidado y agradecimiento.

Por otra parte, los ecoaldeanos establecen un vínculo dialógico con la Tierra. El humano tiene la capacidad de entablar una relación 
comunicativa con ella; es decir, al territorio se le puede sentir y él es capaz de escuchar, bendecir y sanar, entre otras cosas.

Los ecoaldeanos validan una multiplicidad de territorios, que deben ser vivos y libres, es decir con la menor injerencia antropocéntrica. Se reconoce el territorio como sujeto de derechos que debe ser liberado de la explotación humana. A partir de la libertad del territorio de mantenerse natural, se asegura su capacidad de dar vida en sus distintas manifestaciones.

Concretamente el territorio rural, a diferencia de otros, es considerado por los ecoaldeanos un espacio de paz, tranquilidad y alegría. También sana al humano a partir de su esencia, es decir con lo natural, habitando y siendo uno con él. Así, el territorio se constituye como un componente inseparable de la naturaleza humana; el ser humano estaría conformado por el propio territorio: agua, aire, tierra y fuego.

En las entrevistas a sus miembros, estos declaran que, primero, el territorio iniciaría en cada ser, en cada cuerpo. Cada uno edifica y construye su territorio desde lo que es. Luego, está el otro territorio, que es en donde se habita, en el cual hay que adecuarse en el respeto y el amor. Así, el territorio es sagrado, una extensión del propio cuerpo o corazón, un espacio donde el ser, el pensar y el sentir tienen la base para desarrollarse.

El territorio donde se vive es concebido como una concesión, puesta a su servicio para cuidarle, disfrutar, estar en paz, cultivar, compartir con otras personas y todos los seres que lo habitan. El territorio es un espacio que se cuida, pero al mismo tiempo cuida y se convierte en una plataforma para realizar sueños. Es decir, es un ambiente de crecimiento, armonía, familia, resiliencia, comprensión y amor. Más que una propiedad de terreno, se considera como todo lo que les rodea. Es entendido como un proyecto de vida, donde se puede tener trabajo, recreación, tranquilidad y refugio. A su vez el territorio es el que da identidad, pertenencia y enraizamiento.

Con base en algunas observaciones obtenidas a partir del diario de campo, se puede indicar que los ecoaldeanos mantienen prácticas ecológicas para un relacionamiento sano con el territorio, como agroecología, bioconstrucción, biofiltros, permacultura y otras prácticas sustentables para su aprovechamiento. También llevan a cabo ceremonias de agradecimiento y rezos por el territorio. Los ecoaldeanos manifiestan que la acción que realizan es la de "laborar" sobre el 
territorio (orar en la labor), es decir un trabajo consiente de cada acción que desarrollan. Para ellos, además de la Tierra, el agua es un componente fundamental del territorio, el cual es un espacio para el compartir con los demás (voluntarios, vecinos, visitantes y otros).

Al mismo tiempo, los ecoaldeanos participan en acciones para que el Estado reconozca los derechos de la Madre Tierra. Por ello movilizan la creación de comunidades que defiendan el territorio — caso evento "Llamado de la montaña" —. El amor a la Madre Tierra es lo que une los diferentes proyectos sustentables, de transición o de ecoaldeas. Estos deciden cuidar, acompañar y sanar la naturaleza y la Tierra. Además, estos proyectos entienden a la Madre Tierra como la gobernante, a quien se debe obedecer para lograr una existencia en equilibrio con todo lo que nos rodea.

\subsection{Resignificaciones EN RELACIÓN CON LA COMUNIDAD}

Luego de analizar sus discursos, se distingue la manera como los ecoaldeanos entienden la comunidad. Un aspecto por destacar es que el sentido de pertenencia a una comunidad se comparte y refuerza a través de los cantos, ya sea a través del discurso como tal o por su forma de representarlo - en coro, en círculo, rotando la primera voz, rotando tambores y maracas-, lo cual permite expresar canciones propias o integrar versos a otras.

En sus letras se evidencia que los ecoaldeanos tienen un fuerte sentido de pertenencia a una comunidad, ligada a la tierra bajo un sentimiento afectivo de familiaridad. Este sentimiento se demuestra en el elemento "familia", abierto no solo a la unión consanguínea, sino a los voluntarios, vecinos, amigos, seres vivos y otros seres. Los seres humanos y no humanos estaríamos relacionados por descender de una misma progenitora, la Tierra. Por ello se amplía el concepto de comunidad, este abarca no solo a los humanos, sino a los demás seres (árboles, nubes, ríos, piedras, animales, plantas, etc.). Las personas que desean estar vinculadas de manera armónica con la Tierra son entendidas como una sola comunidad. Es decir, las diferentes ecoaldeas o proyectos sustentables o de transición - hasta personas nómadas - son reconocidos como un componente necesario y valorado para lograr el proyecto común. También cabe resaltar que el sentimiento de pertenencia a una raza, tribu o familia es algo reiterativo en el pensamiento ecoaldeano. Esto crea una identidad mayor. 
En su pensamiento, los ecoaldeanos presentan una conciencia colectiva más valorada que una individual. Ellos son quienes conforman a la comunidad y, a la vez, sus subjetividades son constituidas por ella. La individualidad y la colectividad se van cocreando. Todos son interdependientes, partes interrelacionadas e integradas a una totalidad. Por ello se comprende el deber de compartir todo lo que se tiene con las demás personas y seres.

En las entrevistas a los integrantes de la ecoaldea, estos indican que Anthakarana es familia, no solo consanguínea, sino aquella encontrada en el territorio, en las personas, en los llamados de la montaña, en la red nacional de ecoaldeas. Existe un sentimiento de tribu, identidad, similitud, a través de un reconocimiento de que son personas quienes atraviesan un proceso semejante y de aprendizajes colectivos. Son individuos que se reúnen al encontrarse en un territorio, conviviendo y reconociéndose.

Los núcleos familiares tienen como prioridad el buen vivir. Cada uno tiene sus prácticas espirituales o de crecimiento personal, las cuales les permiten involucrarse mutuamente y pensar y a actuar en pro de los demás. La vida en común los lleva a reflexionar sobre cómo servir, es decir, a pensar qué pueden hacer para que todos estén bien; qué pueden hacer para otros y estos qué pueden hacer para ellos. Así, el bienestar común deriva de un bienestar individual y de uno propio.

También expresan que todos los miembros tienen una relación de mucha confianza, entrega, compromiso y transparencia. En la vida comunitaria existen principios cooperativos; por ejemplo, el dinero y los gastos son compartidos; las huertas tienen tenencia conjunta y, por lo tanto, lo producido también. Todos son responsables de los niños.

Con base en algunas observaciones durante mi estadía, se puede señalar que el sentimiento de comunidad se comparte con cualquiera que llega al territorio. Desde un inicio se establece una relación de familiaridad. Al final, muchos lazos que se forjan en la comunidad perduran a pesar de no vivir juntos.

En la ecoaldea existen espacios para reafirmar el sentido de comunidad y pertenencia, como las ceremonias, almuerzos, trabajos comunales y celebraciones. Los trabajos son compartidos, al igual que los beneficios que derivan de ellos. La comunidad se preocupa por 
el bienestar físico y mental de sus integrantes. La vida en comunidad es planificada y organizada por sus miembros. La división del trabajo es esencial para alivianar cargas individuales. Se observa que la comunidad Anthakarana no está cerrada a ella misma, también participa y coopera con otras de su propia vereda, además de las de la red de ecoaldeas.

La existencia de pocos miembros hace más notable la necesidad misma de comunidad e interacción con otros. Los integrantes hacen esfuerzos para mantener sanas y sólidas las relaciones con los demás. La participación en redes también es esencial para la comunidad. Al mismo tiempo es evidente que el concepto de familia y comunidad abarca más que a personas, también incluyen a los demás seres animados y no animados, materiales o inmateriales.

Las diferentes comunidades (ecoaldeas y proyectos sustentables y de transición) pueden ser conformadas por personas de diversas nacionalidades y culturas. Estas gestionan espacios y plataformas para que pueda expresarse y reconocerse en la diversidad. En ese sentido, los ideales colectivos que unifican a estas comunidades son: cuidado de la Madre Tierra, sustentabilidad, permacultura, buen vivir, consumo responsable, resiliencia, proposición y acción en lugar de crítica.

\subsection{Resignificaciones En RELACIÓn CON EL DESARRollo}

A partir del análisis del discurso se indica cómo los ecoaldeanos entienden el desarrollo. En primer lugar, este se asocia con un proceso interno y emotivo, el cual está ligado a un reconocimiento esencial de la vida y la espiritualidad. En segundo lugar, el desarrollo más que una categoría teórica o plan a futuro, se le concibe como un proceso cotidiano - camino, misión y cambio-. Es un proceso en el presente el que conduce sus ideales de desarrollo; es decir, sus acciones cotidianas y sostenidas tienen mayor valor que el objetivo de desarrollo en sí mismo.

Para los ecoaldeanos el ideal de desarrollo tiene estrecha relación con la sostenibilidad medioambiental. Está basado en la capacidad de ser y no de tener, como lo plantearía el desarrollo hegemónico. Tampoco reside en la capacidad de acumular o consumir, sino más bien en la facultad de regenerar — cuidar, cosechar, cultivar, amar-. 
Los estados meta del desarrollo serían: paz, armonía y alegría, lo que circunscribe la felicidad - como finalidad del desarrollo- a acciones concretas de trabajo comprometido sobre el territorio.

El camino al desarrollo que pretenden los ecoaldeanos está ligado a un decrecimiento o retorno a un estado previo de relación armónica con la vida y la Tierra. Por ello, se tiene interés en revalorizar las prácticas y conocimientos indígenas o ancestrales. Una manera de hacerlo es adoptando los paradigmas del buen vivir y la ley de origen. Algo similar a lo que plantea Hernández Umaña (2017).

En sus cantos se evidencia que los ecoaldeanos son conscientes de los efectos negativos que ha provocado el desarrollo hegemónico y la urgencia de cambiar de trayectoria; una ligada a vivir en armonía con la naturaleza para restaurar el equilibrio con ella. El desarrollo debe girar en torno al amor, el cuidado y el respeto por la vida. El ideal que debe alcanzar la humanidad es aprender a cuidar y cultivar la vida.

Se expresa que el desarrollo anhelado consiste en vivir en una realidad material de forma natural, pero sin olvidar el desarrollo interior o espiritual. El de tipo espiritual tiene como propósito deseado trascender el plano material y unirse con la totalidad o con la profundidad de la existencia. Desarrollar un proceso espiritual implicaría liberar los aspectos negativos de la personalidad y las subjetividades, que permitirían justamente la cocreación y disueño ${ }^{12}$ de otra realidad material.

El desarrollo que persiguen los ecoaldeanos se lograría desde las acciones personales, que luego impactarían en las estructuras externas. Este desarrollo personal tendría como fin alcanzar un estado de bienestar, comprendiendo siempre que ese estado se encuentra al ser/estar cercano a la naturaleza.

Enmarcado en un pensamiento en espiral ${ }^{13}$, el camino para desarrollarse como ser humano sigue una dirección hacia el interior del propio individuo, no hacia el exterior o la materialidad de la existencia.

12 Palabras o expresiones alternativas que ofrecen una visión evolucionada y consciente del lenguaje. Cocreación: acción y efecto de crear desde la inteligencia colectiva y bajo modos también colectivos e interrelacionados. Disueño: acción de diseñar soñando, capacidad de concretar un sueño.

13 Modelo de pensamiento holístico que parte de una comprensión donde cada acontecer está estrechamente relacionado con otros acontecimientos, produciendo nuevas relaciones y eventos en un proceso que siempre compromete al todo, como una espiral. 
Al transformar lo que el individuo siente, percibe o vive en su interior, está en la capacidad de crear mejores condiciones de una realidad externa.

Bajo una comprensión cíclica o en espiral, el tiempo lineal se deconstruye y también la temporalidad se comprende como un proceso cíclico que conduciría nuevamente a atravesar los mismos estadios en circunstancias distintas. En ese entendido, es interesante pensar que el "desarrollo" no sería un estado de culminación, ni un estado que se debe encontrar en el futuro, como lo ha planteado la ontología moderna y occidental. En su lugar, el "desarrollo" se podría encontrar en el pasado. Retornando al inicio es como se debe avanzar.

Se observa la integralidad de la comprensión de desarrollo. Desde esa perspectiva, se opta por no separar lo tangible de lo intangible de la existencia, y, por tanto, se busca complementar, a través de unos modos de vida coherentes, sus pensamientos, palabras y acciones.

A partir de la observación participante, los ecoaldeanos señalan la existencia de las necesidades materiales; en ese sentido, para ellos el dinero es un medio para satisfacerlas y no un fin. Por ello establecen microemprendimientos ${ }^{14}$ los cuales pueden adaptar a sus posturas ético-políticas, además de obtener dinero de/con su territorio ${ }^{15}$. En cuanto al consumo, intentan hacer un uso consciente ambiental y energéticamente; es decir, que el producto adquirido sea sustentable en ambos sentidos. La necesidad y la funcionalidad priman como parámetros de consumo sobre el deseo y la estética. Se evita consumir más de lo necesario, se prefiere reparar, reutilizar o reciclar.

El desarrollo ecoaldeano se ve plasmado en su cotidianidad; por ejemplo, la labor física y constante sobre el territorio, ya sea con sembradíos o con animales. Para su aprovechamiento se implementan cultivos orgánicos, bioconstrucción y principios permaculturales. Producen alimentos para autoconsumo y en mínima cantidad para la venta. En ese sentido, velar por la sanidad de sus alimentos es más importante que cualquier superávit por ventas. Por otra parte, los ecoaldeanos también aprecian más su tranquilidad y otros sentimientos sobre sus

14 Toallas higiénicas femeninas de tela, cerveza artesanal, productos agroecológicos, entre otros. 15 Estadías, ceremonias y eventos pagados, entre otros. 
pertenencias materiales. El tiempo libre es más valorado que la generación de capital, y el territorio y el agua son más apreciados que el dinero. Los ecoaldeanos se consideran responsables de su propio desarrollo. Para ellos este debe ser integral, es decir la unión entre aspectos individuales, comunitarios, ambientales y territoriales. También se observa que las ceremonias espirituales son hitos importantes en el desarrollo personal.

Los lineamientos del desarrollo ecoaldeano planteados en el Llamado de la Montaña 2020 señalan a manera de ejemplo el buen vivir, la ley de origen, la soberanía, la sustentabilidad y la autonomía territorial y administrativa, la solidaridad y la sociocracia como forma de gobierno y toma de decisiones. Estos se constituyen como ideales en el desarrollo, que unen las diferentes comunidades (ecoaldeas).

En las entrevistas a los integrantes de la ecoaldea, estos indican que su desarrollo consiste en tener lo que necesitan en la medida justa. Es decir, el justo medio entre lo que alguien quiere como persona y lo que es mejor para la comunidad; un equilibrio entre las necesidades de la comunidad y del territorio. También expresan que la meta del desarrollo es ser un buen ser humano. Los indicadores para ello son tener un territorio para cuidar, un techo, compañía, ser querido por otros, tener salud, alimento sano y tranquilidad.

El desarrollo también es comprendido como las manifestaciones personales del buen vivir: necesitar poco para vivir mejor, cuidar de la biodiversidad y generar procesos de aprovechamiento coherentes. Por ello, la sustentabilidad y regeneratividad se consideran pilares de su desarrollo.

Para los ecoaldeanos, el desarrollo parte de pensar en el bienestar de todos; no se podría hablar de desarrollo si no se habla de un colectivo. Se debe comprender el bienestar humano no solamente como individuo, sino como grupo, por lo cual se debe volver la mirada a lo igualitario, a lo común, para volver a ser unidad. Por otra parte, el desarrollo es comprendido como vivir en la no violencia, tener una economía que permita vivir dignamente y gozar de un equilibrio entre lo que se quiere, se necesita y se puede.

Para profundizar en dos aspectos que se reiteran en las entrevistas -buen vivir y ser buen ser humano- se realizó un grupo focal mediante el cual se pudo entender el buen vivir como: coexistir con un bienestar que no afecte el de las demás personas ni de la Tierra; 
construir un bienestar personal con un bienestar de la naturaleza; vivir conectado, en paz y armonía, con la naturaleza, el agua y la Tierra; tener un equilibrio entre lo que se consume, lo que produce y lo que se devuelve a la Tierra; respetar el territorio; y usar los recursos estrictamente necesarios sin aprovecharse de ellos.

El buen vivir también se traduce en tener un espacio para cultivar, comer y vivir sanamente; tener buenas prácticas para el disfrute de la vida en conciencia y acción constante; tener buena comunicación entre el mundo externo e interno; tener economía y tiempo para una calidad de vida; tener techo, territorio, alimentos, aire, agua, tiempo libre y estar rodeado de personas buenas; y mantener un balance entre las normas económicas y las prácticas espirituales y ecológicas.

En cuanto las prácticas que los ecoaldeanos implementan para un buen vivir están: sembrar orgánicamente, realizar prácticas ecológicas, cuidar el medioambiente, construir viviendas con materiales biodegradables, ecológicos o reutilizados, compartir vehículos, tener buena alimentación, realizar prácticas espirituales, disfrutar el tiempo libre, tener una comunicación no violenta, agradecer por todas las relaciones - humanas, minerales, vegetales, animales, con toda la vida - y estar en paz con ellas.

En cuanto a ser buenos seres humanos, las comprensiones son las siguientes: no hacer daño a los demás, cuidar sus relaciones, estar al servicio de los demás en grado máximo y tener la condición de dar y buscar el amor. Da sin esperar, teniendo amor propio y para los demás. Un buen ser humano también se hace responsable de las propias acciones y emociones, y asume las consecuencias emocionales, mentales y físicas de sus decisiones. Además, es coherente con lo que se piensa, hace y dice. Un buen ser humano es capaz de hablar, vivir y actuar en coherencia espiritual, sentimental y con sus necesidades. También es quien tiene ecuanimidad frente a lo que quiere y puede.

Por otra parte, un buen ser humano es responsable, respetuoso de la vida, de sus acciones y del medio ambiente. Asimismo, es consciente de que hace parte de un todo y que sus relaciones son horizontales e interdependientes. Para los ecoaldeanos, las cualidades de un buen ser humano son: ser transparente, confiable, respetuoso, justo, bondadoso, servicial, honesto, saber comunicarse y ser consciente del accionar, pensar y sentir. 


\section{AnÁlisis transversal}

Los ecoaldeanos, a través de la implementación sus prácticas comunicativas particulares agencian el proceso performativo del lenguaje. Es decir, la representación, sobrerrepresentación y desrepresentación de los referentes mediante los que se direccionan a los sujetos para reproducir patrones simbólicos determinados (Butler, 2014). Tal agenciamiento tiene el poder de introducir distintas acepciones que modifican el significado de los conceptos que deseen. En este caso particular se exponen las interpretaciones alternas sobre territorio, comunidad y desarrollo presentes en la Ecoaldea Anthakarana, complementadas por el Llamado de la Montaña 2020. Con ello, se observa que las ecoaldeas rompen la interpretación hegemónica de estas categorías y además logran, en cierta medida, descomponer las acciones y justificaciones que devienen de las antiguas significaciones, superando así la simple crítica discursiva y experimentando vivencialmente estas resignificaciones.

Se puede señalar que los resignificados (territorio, comunidad, desarrollo) adquiridos socialmente (en común-unidad) en contextos particulares (a través de prácticas comunicativas) y en marcos simbólicos diferenciales (ontología relacional) definen de manera singular la subjetividad y la identidad colectiva expresada en acciones. Algunas de estas acciones son considerables, como dejar de vivir en la ciudad, dejar de trabajar asalariadamente, renunciar a una formación académica; y otras son cotidianas, como usar sanitarios secos, cultivar con abonos ecológicos, colocar biofiltros para las aguas, construir con materiales biodegradables, disminuir el consumo de productos industrializados, evitar consumir plásticos de un solo uso, compostar, reciclar, reparar, compartir, cocinar y almorzar en comunidad, laborar, compartir medicinas, entre otras.

A través de la inmersión en el territorio y compartir su modo de vida por varios meses, evidencié que sí existe una resignificación, en tanto la relación entre discurso y acción es coherente. En la Ecoaldea Anthakarana, las personas, sus acciones y sus versiones del mundo se han transformado de manera sincrónica con las resignificaciones en torno a las categorías de territorio, comunidad y desarrollo. También pude expandir superficialmente el análisis hacia otro territorio - Proyecto Gaia - y con muchos miembros de diversas ecoaldeas —Llamado de la montaña 2020 - Con base en ello, se puede señalar 
que las ecoaldeas, como un fenómeno alternativo de ser/hacer/pensar, permiten la inclusión de enunciados disyuntivos que son consecuencia de su interacción cotidiana y sus prácticas comunicativas. De igual modo, se perciben deliberadamente como procesos de alterización del mundo único en reafirmación de un mundo otro.

Al respecto, entre las principales resignificaciones de la categoría territorio se expone que, para los ecoaldeanos, esta no solo se refiere a la Tierra, sino que está asociada también al agua y al aire. De esta manera se reconoce no solo el espacio, sino los otros elementos, que permiten la subsistencia, como inherentes al mismo. De igual modo se reconoce el territorio como el ente que genera y soporta la vida, y se le considera sagrado. Así mismo, es sagrado por ser la extensión del propio cuerpo individual, un espacio donde el ser, el pensar y el sentir tienen la base para desarrollarse.

Por otro lado, se concibe una relación afectiva con el territorio - como madre de la vida - con la cual se puede entablar una relación dialógica comunicativa a través de prácticas para su aprovechamiento consciente y respetuoso, y prácticas de agradecimiento para restablecer el equilibrio con ella. Es a partir de esta relación que se obtienen los sustentos materiales y espirituales. Así también se reconoce al territorio como un ser vivo, sintiente y sujeto de derecho que debe ser liberado de la explotación humana para asegurar su capacidad de dar vida en sus distintas manifestaciones. En síntesis, comprenden un "territorio sujeto vivo".

La principal resignificación de la categoría comunidad que se formula desde la ecoaldea, es que esta se amplía no solo a grupos humanos, sino a toda la diversidad de los componentes de la vida, desde los seres biofísicos y elementos, hasta otros que no pueden ser encasillados en la materialidad pero que, aun así, interaccionan con ella. Los ecoaldeanos logran esta ampliación al comprender las interrelaciones codependientes individuales por/con toda la vida que genera una común-unidad. Con ello también deciden que sus relaciones se basan en un sentimiento afectivo de familiaridad y cuidado; al ser todos hijos de la Tierra y la vida, todo es familia. Dicho de otra forma, comprenden una "común-unidad de la vida".

Al contrario del ideal de desarrollo representado por el aprovechamiento ilimitado de recursos, en un continuo círculo de producción y consumo insostenible (Bautista, 2017), el modelo de desarrollo ecoaldeano se 
caracteriza por aprovechar estrictamente lo necesario de los recursos. En consecuencia, la naturaleza no es forzada a satisfacer la hiperproducción, sino que es respetada en sus ciclos regenerativos para asegurar su sustentabilidad. Esto se encuentra en coherencia con la comprensión de que un deber humano es asegurar el equilibrio para la continuidad de la vida.

También es notable que el ideal de desarrollo se asemeja al decrecimiento (Latouche, 2009), ya que es un proyecto local (ecoaldea como proyecto colectivo basado en el territorio), que piensa globalmente (cambio climático, crisis civilizatoria) y actúa localmente (experimentar un proyecto de vida que sirva de ejemplo para los demás). De igual modo, considera relevante el autogobierno y la autosuficiencia alimentaria y financiera (aunque no logren cumplirlos). Al mismo tiempo, se asemeja a la propuesta de Hernández Umaña (2017), quien trata de suscitar acciones locales para lograr efectos globales. Para ello, expone que el ser humano debe llevar a cabo procesos de autoconocimiento y autoobservación, manteniendo relaciones basadas en el amor consigo mismo, con los demás seres humanos y la comunidad de la vida, comprendiendo las acciones de la mente - pensamientos, sentimientos y acciones - para que conduzcan a un pensar bien.

Una de las principales resignificaciones de la categoría desarrollo que se formulan desde la ecoaldea, consiste en abolir la concepción de crecimiento económico con la que se asocia. A su vez, desvía la idea antropocéntrica e individualista de esta categoría y en su lugar presenta características de un "desarrollo biocéntrico, comunal e interno".

"Desarrollo biocéntrico", ya que los ecoaldeanos tienen una conciencia $^{16}$ de que su existencia no está separada de la naturaleza y son codependientes de las relaciones que tienen con todo el sistema biofísico de la Tierra y sus seres. Por ello su desarrollo está ligado a la sustentabilidad en primera instancia y a la regeneratividad como

16 Morin, citado por Hernández Umaña (2017), señala que la toma de conciencia ecológica de nuestra condición terrena, que comprende nuestra relación vital con la biosfera, conduce a abandonar el sueño del dominio de la naturaleza por la aspiración a la convivencialidad en la Tierra. Esta última no sería la adición de un planeta físico, de una biosfera y de una humanidad; sino que sería una totalidad compleja física-biológica-antropológica, en la que la vida es una emergencia de la historia de la Tierra; el humano, una emergencia de la historia de la vida. Por lo tanto, la humanidad se constituye como una entidad planetaria y biosférica. 
nivel ideal. Para alcanzar el desarrollo biocéntrico se postula un decrecimiento o retorno a un estado previo de relación armónica con la vida y la Tierra. Es así como los paradigmas del buen vivir y la ley de origen son adoptados como guías principales.

El desarrollo ecoaldeano integra los sistemas de vida orgánicos y reconoce la interconexión e interdependencia de sus relaciones. Esto limita su explotación y violencia, generando en su lugar reconocimiento, agradecimiento y devolución de los componentes que permiten perpetuar los sistemas de vida orgánicos. Lo anterior se traduce en vivir en armonía con la Tierra y la vida.

"Desarrollo comunal", ya que parte de pensar en el bienestar del colectivo en su conjunto. Desde una conciencia colectiva y cooperativa, las necesidades se cubren en primera instancia en conjunto y con ello se aseguran, en gran parte, las necesidades individuales. Además, el desarrollo ecoaldeano busca ser un equilibrio entre las necesidades individuales y comunitarias, al mismo tiempo de serlo con las necesidades ambientales y territoriales, ya que, como se mencionó, la comunidad abarca estos otros aspectos.

El desarrollo comunal refuerza los lazos familiares y comunitarios, y también provee mayor tiempo libre, lo que permite utilizar la energía conservada en espacios participativos, recreativos, colaborativos y de organización comunal. Con menor tiempo invertido en suplir las necesidades en conjunto, los ecoaldeanos están en la capacidad de dedicarse a satisfacer su "desarrollo interno", que está enmarcado en un pensamiento en espiral. El camino para desarrollarse como ser humano sigue una dirección hacia el interior del propio individuo. La importancia de las prácticas espirituales o de crecimiento personal que conducen a ser consciente que como individuo se hace parte de una totalidad y que por lo tanto se debe cuidar de todas las relaciones, estar al servicio de lo demás y tener la condición del dar y buscar amor, es esencial para resignificar tanto la categoría de desarrollo, como también la de comunidad y territorio, manteniendo en su interior la comprensión de que se vive para sí y para el/lo otro.

Como se analizó, la dependencia de los significados en su representación y reiteración dentro de los discursos, que a su vez se enmarca dentro de prácticas comunicativas concretas, hace que la Ecoaldea Anthakarana, al agenciarse de prácticas comunicativas y discursos propios, pueda 
alterar los significados de territorio, comunidad y desarrollo. En este caso, las resignificaciones de las tres categorías están interrelacionadas. Es a partir del nuevo significado de la común-unidad de la vida y del territorio sujeto vivo que se moldea la categoría de desarrollo biocéntrico, comunitario e interno. También queda evidencia que este cambio de comprensiones se fundamenta en una ontología relacional. De otra manera no se podrían concebir las relaciones que subyacen de estos modos de ser, pensar y hacer.

\section{Conclusiones}

Este trabajo de investigación analizó la manera en que las prácticas comunicativas de los miembros de la Ecoaldea Anthakarana se basan en una ontología relacional y la reproducen, ya sea con discursos o actos. En ambos casos, se evidencia la existencia de una resignificación de las nociones de desarrollo, territorio y comunidad, las cuales no están alineadas con las lógicas de la modernidad occidental y el capitalismo global. El impacto de las prácticas comunicativas, desarrolladas desde otras epistemes y ontologías, confronta la hegemonía de la modernidad occidental, y a su vez un antropocentrismo depredador y causante del desequilibrio ambiental. Las resignificaciones que surgen de dichas prácticas construyen un marco interpretativo que reconfigura unas acciones, deberes y responsabilidades con la Tierra, la vida y todos los seres, entendidos como parte de la misma totalidad.

En ese sentido, las prácticas comunicativas descritas demuestran que los ecoaldeanos poseen un marco referencial distinto al de la ontología dual o moderna. Siendo este una de las principales causas y sustentos para transformar sus compresiones acerca de las categorías analizadas. Esto debido a que su ontología relacional establece unas lógicas distintas para entender el mundo y actuar en correspondencia. La relacionalidad que plantean supone una nueva forma de entender nuestra relación como seres humanos — desde el campo físico y moral - con el resto de seres vivos. De igual modo, se concibe el planeta como un organismo basado en relaciones corresponsales que permiten la continuidad de la vida. Aquí no cabe la consagración egoísta de ningún ser en particular, pues la existencia de todos depende del mantenimiento sano de las relaciones planteadas. 
El trabajo de investigación señala que los miembros de la Ecoaldea Anthakarana comprenden nuevas formas del desarrollo, desde una postura de desarrollo biocéntrico, comunitario e interno. Tal postura se encuentra estrechamente interrelacionada con las compresiones de común-unidad de la vida y del territorio sujeto vivo. Estos conceptos constituyen planteamientos alternativos a las nociones tradicionales de comunidad y territorio. Estos planteamientos se esbozan para que puedan seguir siendo construidos con base en nuevas investigaciones afines, ya que las contribuciones del fenómeno ecoaldeano son una interesante alternativa al desarrollo, la sociedad y territorialidad hegemónicos. Al integrar discursos y prácticas que permean varios aspectos de la vida humana, los referentes están en constante búsqueda de corregirse y reinventarse con la propia experiencia colectiva. Otros estudios sobre las comprensiones serán enriquecedores para cocrear categorías que se ajusten apropiadamente al fenómeno emergente.

Si bien el fenómeno de las ecoaldeas nace como comunidades intencionadas con un compromiso ecológico, también propugnan -aunque no estén plenamente conscientes de ello- modelos de posdesarrollo, decolonialidades del poder y el saber, epistemologías del sur, heterotopías y otras propuestas antisistémicas posibles y actuales. En consecuencia, en el ámbito rural surgen nuevos escenarios relacionales poco conocidos, donde los procesos comunicacionales constituyen estrategias de cambio social, los cuales pueden estar articulados con nuevos procesos investigativos y nutrirse mutuamente. Por lo tanto, será importante continuar visibilizando sus aportes, ya sea en la academia o en el público en general, para que surjan más y mejores experiencias que busquen subsanar las problemáticas de la actual crisis civilizatoria y ambiental. Así mismo, sería interesante indagar en otros aspectos de la comunicación -mediática, virtual, educativa, política, etc.- que estén relacionados con el cambio social que procuran. Los nuevos abordajes pueden considerar la investigación como una forma de intervención en la sociedad, a partir de la consolidación y devolución de conocimientos que posibiliten transformaciones concretas.

Por otra parte, esta exploración puede brindar muestras que sirvan para generar procesos comunicativos-participativos, que, desde la autonomía local, contribuyan a la formación de nuevas identidades que incidan en la esfera pública. Ello al visibilizar y analizar 
distintas narrativas y discursos como escenarios de significación y enunciación del individuo y la colectividad. También se podría profundizar en las contribuciones de las prácticas comunicativas, narrativas y discursos ecoaldeanos que afianzan el tejido social para reconstruir la vida en comunidad y la convivencia, incluso la consolidación de la paz. A su vez, es posible analizar las tensiones entre el poder global derivado del capitalismo y desarrollismo, y los procesos de resistencia local gestados por comunidades y distintos actores sociales, que luchan por el reconocimiento de otros saberes y formas alternativas de desarrollo sustentadas en la común-unión de la vida. Así mismo, continuar estudiando la relacionalidad y el biocentrismo como nociones eco, ético, políticas emergentes y primordiales para transformar identidades, ideales, pautas y comportamientos sociales que produzcan nuevamente un equilibrio en donde se asegure la continuidad colaborativa de todas las formas de vida.

Naurenda, Bolivia. 2021

\section{REFERENCIAS}

Aleman, Q. M. (2017). Las representaciones sociales del Buen Vivir en las ecoaldeas: el caso de Aldeafeliz, San Francisco, Cundinamarca [tesis de maestría, Universidad Distrital Francisco José de Caldas]. Repositorio institucional Universidad Distrital Francisco José de Caldas. https://bit.ly/3eF5yxe

Bautista, R. (2017). Del mito del desarrollo al horizonte del "vivir bien": ¿por qué fracasa el socialismo en el largo siglo XX? Yo soy si Tú eres Ediciones.

Buil, M. (2007). Sostenibilidad en pequeñas comunidades rurales: análisis de los valores y comportamientos de las relaciones intrapersonales, interpersonales y con el medio, y elaboración de propuestas de mejora para el avance hacia la sostenibilidad [tesis de doctorado, Universidad Autónoma de Barcelona]. Repositorio institucional Universidad Autónoma de Barcelona. https://bit.ly/3eEgpY4

Butler, J. (2002). Discutir con lo real. En Cuerpos que importan: sobre los límites materiales y discursivos del "sexo" (pp. 228-270). Paidós.

Blaser, M. y De La Cadena, M. (2009). Introducción. Red de Antropologías del Mundo World Anthropologies Network, (4), 3-9. https://bit.ly/3eEvVmD

Consejo regional indígena del Huila (CRIHU). (2013, 18 de julio). La Ley Origen de los pueblos indígenas. https://bit.ly/3eIcycs

De la Morena, G. V. (2017). Sembrando el Espíritu de Gaia: prácticas de comunicación para una transición ecosocial hacia la sustentabilidad [tesis de maestría Corporación Universitaria Minuto de Dios]. Repositorio institucional Uniminuto. 
Miguel Manchego Chávez - Resignificaciones del desarrollo, comunidad y territorio en las prácticas comunicativas que afirman una ontología relacional. Caso Ecoaldea Anthakarana

Escobar, A. (2005). Mas allá del Tercer Mundo. Globalización y Diferencia. Instituto Colombiano de Antropología e Historia.

Escobar, A. (2012). Cultura y diferencia: la ontología política del campo de cultura y desarrollo. Wale keru, Revista de Investigación en Cultura y Desarrollo, 7-16. https://bit.ly/3zlxApd

Escobar, A. (2014). Sentipensar con la tierra: nuevas lecturas sobre desarrollo, territorio y diferencia. Ediciones Unaula.

Guevara, L. J. (2014) Causas que motivan la conformación de comunidades alternativas como crítica a la sociedad occidental moderna. Caso kunagua, Silvania, Colombia [tesis de grado, Universidad del Rosario]. Repositorio institucional EdocUR. https://bit.ly/2VYPgbM

Gudynas, E. (2017). Posdesarrollo como herramienta para el análisis crítico del desarrollo. Estudios Críticos sobre el Desarrollo, 7, 193-210. https://doi.org/10.35533/ ecd.0712.eg

Hernández Umaña, B. A. (2017). Desarrollo y derecho al desarrollo: Desde el biocentrismo y el pensamiento complejo. Ediciones USTA. https://doi.org/10.15332/li. lib.2017.00001

Herrera, E. R. y Vega, J. H. (2014). Prácticas Comunicativas de participación cultural y memoria biocultural. En A. Cadavid Bringe y A. Gumucio Dagron (eds.), Pensar desde la experiencia: Comunicación participativa en el cambio social (pp. 287-302). Uniminuto.

Latouche, S. (2009). La apuesta por el decrecimiento: ¿cómo salir del imaginario dominante? Icaria Editorial.

Manchego, M. (2020). Resignificaciones en torno al Desarrollo, Comunidad y Territorio fundamentadas en Prácticas Comunicativas que afirman una ontología relacional. Caso Ecoaldea Anthakarana [tesis de maestría, Universidad Santo Tomás]. Repositorio institucional Universidad Santo Tomás. https://bit. ly/3wWYcLB

Muñoz Villarreal, E. M. (2017). Ecoaldeas, tejiendo transiciones hacia el buen vivir. Un estudio de casos en las ecoaldeas Anthakarana y Aldeafeliz en Colombia. Universidad de Caldas.

Martínez Carazo, P. C. (2006). El método de estudio de caso: estrategia metodológica de la investigación científica. Pensamiento \& Gestión, (20), 165-193.

Pinzón, C. M. (2014). Transformación de la Estructura Agroecológica Principal en comunidades intencionales rurales (Ecoaldeas) [tesis de maestría, Universidad Nacional de Colombia]. Repositorio institucional UNAL. https://bit.ly/3BuEwlK

Red Casa Latina. (2019). Qué es sociocracia. https://bit.ly/3BvR8sP

Redtail Freesoul, J. (1986). Breath of the Invisible: The Way of the Pipe. Theosophical Pub House.

Rodríguez, A. (s. f.). Filosofía del Buen Vivir. https://filosofiadelbuenvivir.com/buen-vivir-2/definiciones/

Ruz Buenfil, A. (2006). Las comunidades de intención. En L. Valdés Kuri y A. Ricalde de Jager (compiladores), Ecohábitat, experiencias rumbo a la sustentabilidad (pp 26-29). Instituto Nacional de Ecología. 


\section{ANÁLISIS

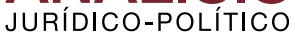

Ruiz y Del Cairo, C. (2016). Los debates del giro ontológico en torno al naturalismo moderno. Revista Estudios Sociales, (55), 193-204. doi:http://dx.doi. org / $10.7440 /$ res55.2016.13

Solórzano Duran, N. S. (2017). Consideraciones sobre la incidencia de la Ecoaldea Aldeafeliz en la producción de alternativas al neoliberalismo en la población de San Francisco, Cundinamarca [tesis de grado, Pontificia Universidad Javeriana]. Repositorio institucional Pontificia Universidad Javeriana. https://bit.ly/3zlx4Yj

Valdes, L. y Ricalde, A. (compiladores). (2006). Ecohábitat, experiencias rumbo a la sustentabilidad. Secretaría de Medio Ambiente y Recursos Naturales. https:// bit.ly/3kMJWmf

Valencia, C. V. y Magallanes, C. (2015). Prácticas comunicativas, creatividad y nuevos desafíos. Universitas Humanística, 81(81). https://doi.org/10.11144/Javeriana.uh81.pces 